\title{
Spatio-temporal movement patterns and habitat choice of red foxes (Vulpes vulpes) and racoon dogs (Nyctereutes procyonoides) along the Wadden Sea coast
}

\author{
Philipp Schwemmer ${ }^{1}$ (D) $\cdot$ Stefan Weiel ${ }^{1}$ (D) $\cdot$ Stefan Garthe ${ }^{1}$
}

Received: 12 June 2020 / Revised: 3 March 2021 / Accepted: 5 March 2021 / Published online: 28 April 2021

(C) The Author(s) 2021

\begin{abstract}
Wetlands such as the World Heritage Site in the Wadden Sea include important habitats for breeding waterbirds. Its saltmarshes and adjacent conservation polders are used by thousands of breeding birds. However, some alarming population declines have been recorded during recent decades and previous studies found indications that predation pressure from red foxes (Vulpes vulpes) and more recently from invasive racoon dogs (Nyctereutes procyonoides) played an important role. The current study aimed to assess habitat utilisation by foxes and racoon dogs along the coast of the Wadden Sea. We equipped 21 foxes and seven racoon dogs with GPS collars and recorded a total of 37,586 (mean: 2,088) GPS fixes during a total of 2,617 (mean: 145) equipment days for red foxes and 3,440 (mean: 573) GPS fixes during a total of 272 (mean: 45) equipment days for racoon dogs. Foxes showed high individual variability in Kernel 95\% home range sizes, with a mean of 172.2 ha (range: 3 to 824 ha) and little overlap among territories. Males had significantly larger home ranges than females, and there were no differences in home range sizes between adults $(n=14)$ and young $(n=4)$. Racoon dogs had smaller home ranges than foxes (mean: $52.8 \mathrm{ha})$. The preferred habitat type of both predators during daytime was the conservation polders along the Wadden Sea, while foxes also selected saltmarshes during the night. In contrast, both species avoided farmland areas. Foxes showed $20 \%$ of their activity during daylight hours and spent this time largely in areas with dense vegetation cover. None of the tagged individuals entered areas with particularly high bird densities (i.e. Wadden Sea islands or Halligen). However, our data suggest that foxes and racoon dogs frequently make use of linear structures such as dykes and dams and patrol along the tide line for carcasses. This suggests that at least single individuals of both species are prone to enter islands that are connected by dams to the mainland.
\end{abstract}

Keywords Home range $\cdot$ habitat use $\cdot$ GPS telemetry $\cdot$ activity $\cdot$ wetland

\section{Introduction}

Wetlands are among the most important habitats for breeding waterbirds worldwide (e.g. Wetlands International 2006; Long et al. 2007; Williamson et al. 2013). However, ground-nesting birds have demonstrated poor reproductive success in various regions around the globe, including birdrelated Special Protection Areas (SPAs), often attributed to

Philipp Schwemmer

schwemmer@ftz-west.uni-kiel.de

$1 \quad$ Research and Technology Centre (Forschungs- und Technologiezentrum), University of Kiel, Hafentörn 1, 25761 Büsum, Germany predation pressures by mammals (e.g. Meisner et al. 2014; Mason et al. 2018; Fiderer et al. 2019).

This situation exists in one of the Europe's largest and most important SPAs in the Wadden Sea, extending from the eastern North Sea at south Denmark across Germany to The Netherlands. Thousands of pairs of 35 different bird species breed on the saltmarshes on the mainland (including the adjacent conservation polders), islands and Halligen (inhabited marsh islands regularly inundated during storm surges) (Bruns et al. 2001; Koffijberg et al. 2015). However, alarming population declines have been reported for most breeding birds, including rare and common species, in most regions of the Wadden Sea (Schwemmer et al. 2014; Koffijberg et al. 2015, 2017). The reasons for these declines vary, but in addition to flooding, predation by terrestrial mammals is one of the main factors affecting the breeding success of ground-nesting birds (Thorup and Koffijberg 2016; Leyrer 
et al. 2019). Previous studies showed that $30-40 \%$ of the clutch losses along the Wadden Sea coast could be attributed to red foxes and up to $30 \%$ to racoon dogs (Cimiotti and Klinner-Hötker 2019; Salewski and Schmidt 2019; Salewski et al. 2019). Given the strong population declines caused by both predator species, conservation agencies along the Wadden Sea are currently discussing management options (Leyrer et al. 2019). However, currently basic information on spatio-temporal movement patterns, habitat selection and home range sizes of red foxes and racoon dogs along the Wadden Sea coast are missing. The main aim of this study was thus to collect basic information on the spatio-temporal patterns of these predators along the Wadden Sea coast using highly precise GPS telemetry, to facilitate the management of important NATURA 2000 bird-breeding sites (e.g. by predator control or suitable habitat management measures; JMBB Joint Monitoring Breeding Bird Group 2013; Leyrer et al. 2019). Our study was not designed to investigate direct effects of both predators on ground-breeding birds.

Red foxes (Vulpes vulpes; referred to as "foxes" below) are native to Central Europe and frequently prey on groundnesting birds, according to various dietary studies (e.g. Gołdyn et al. 2003; Dell'Arte et al. 2007; Rickenbach et al. 2011; Meisner et al. 2014; Elmeros et al. 2018). Although hunting intensity varies among years, annual numbers of hunted foxes reported to the German federal state of Schleswig-Holstein roughly reflect the potential population trends of red foxes (MELUND - Ministerium für Energiewende, Landwirtschaft, Umwelt, Natur und Digitalisierung des Landes Schleswig-Holstein 2018). After a vaccination programme against rabies in Germany during the 1980s, the hunting bag of foxes in Schleswig-Holstein increased to a maximum of around 20,000 individuals at the beginning of the 1990s, and recent numbers have since levelled off at around 15,000 hunted individuals (Fig. 1).
In contrast to red foxes, racoon dogs (Nyctereutes procyonoides) have an even broader dietary niche, including higher proportions of invertebrates and vegetation, but also including birds, particularly during the breeding season (e.g. Sutor et al. 2010; Kauhala and Ihalainen 2014; Elmeros et al. 2018; Salewski and Schmidt 2019). The diet choice of racoon dogs has been described as opportunistic, and individuals often select superabundant prey types (Kauhala et al. 1993; Sutor et al. 2010). Racoon dogs invaded Central Europe after introduction into the European part of Russia between 1929 and 1955, with the first records in eastern Germany in 1964 (Nowak 1973). Several studies using ear tags and radio telemetry have documented this species' strong dispersal ability (e.g. Sutor 2008; Drygala et al. 2010). Following a southeast to northwest movement, racoon dogs have also invaded the federal state of Schleswig-Holstein (Schmüser et al. 2019) and are now abundant along the Wadden Sea coast. The hunting bag of racoon dogs in Schleswig-Holstein reflects the strong population increase of this invasive species (Fig. 1). The first racoon dog in Schleswig-Holstein was recorded in 1974 (Heidemann 1975) and the first individual was shot in 1982 (MELUR 2018), while the hunting bag of racoon dogs has increased exponentially since the beginning of the twenty-first century (Fig. 1).

Although habitat use by foxes has already been studied using telemetry at various inland sites (e.g. Bischof et al. 2018; Fiderer et al. 2019), according information in coastal areas is scarce. A pilot study in Denmark analysed the spatial behaviour of three individuals close to the coast (Meisner et al. 2014). So far, this is the only availably study on movement patterns of red foxes in a polder system along the Wadden Sea coast

Similar to foxes, the activity patterns of racoon dogs have mostly been analysed in inland systems using VHF telemetry (Drygala et al. 2008a, 2008b, 2008c; Sutor 2008; Drygala
Fig. 1 Hunting bags of foxes and racoon dogs caught in the federal state of Schleswig-Holstein, north Germany (data source: MELUND - Ministerium für Energiewende, Landwirtschaft, Umwelt, Natur und Digitalisierung des Landes Schleswig-Holstein 2018)

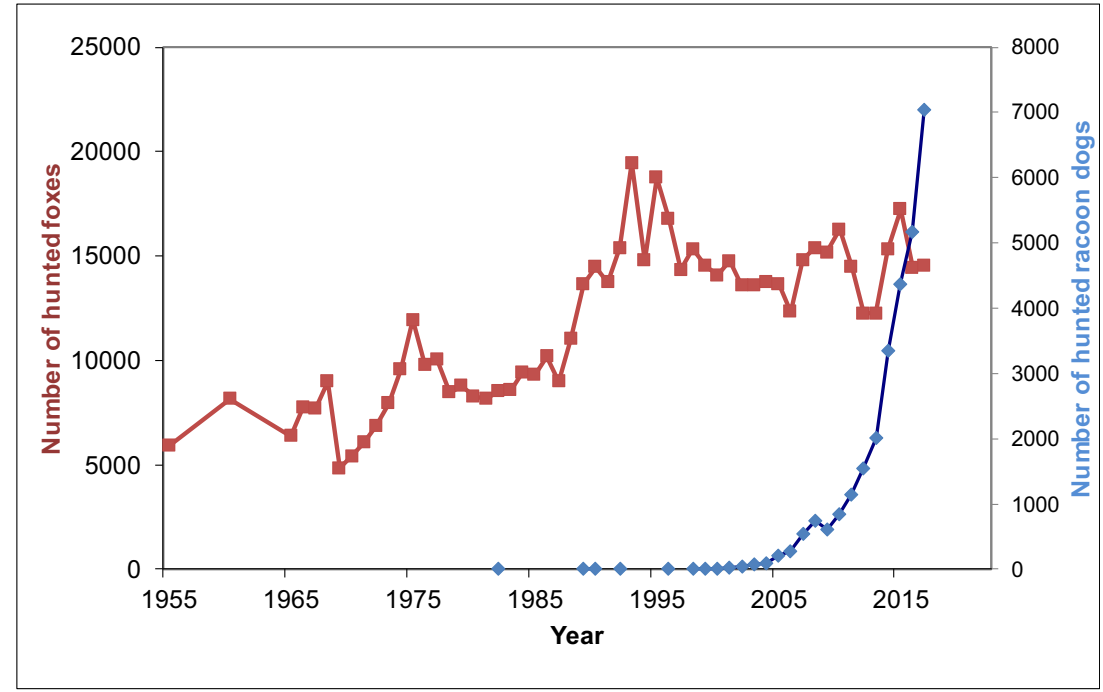


et al. 2010; Drygala and Zoller 2013; Zoller and Drygala 2013), while information on habitat use by this species along the coast, adjacent to one of the Europe's most important SPAs, is still missing.

The Wadden Sea coastline consists of a mosaic of different habitat types (i.e. islands, saltmarshes, conservation polders (embanked land now mainly used for nature conservation) and areas with intensive farming). Suitable breeding habitat for coastal birds in the Wadden Sea has declined as a result of ongoing sea level rises, coastal protection measures and intensive agriculture (e.g. Hofstede 2019). This coastal squeezing effect is further amplified by intensive predation pressures from terrestrial mammals such as foxes and the invasive racoon dog (Leyrer et al. 2019; Salewski and Schmidt 2019; Salewski et al. 2019). Coastal protection measures, such as the reinforcement of dams connecting Halligen (i.e. highest density areas for breeding birds) to the mainland, have increased the predation of breeding birds by foxes (Drost 2013; Schiffler et al. 2018; Leyrer et al. 2019). On Hallig Oland, severe losses among gulls and terns occurred and a spoonbill (Platalea leucorodia) colony on the Hallig got extinct since ground predators were able to regularly visit the Hallig (Schiffler et al. 2018; Leyrer et al. 2019). The occurrence of non-endemic terrestrial mammals on the islands and Halligen has been listed as an indicator within the Marine Strategy Framework Directive by the OSPAR commission (https://www.ospar.org/; OSPAR 2013). However, the movements, activity budgets and home range sizes of foxes and racoon dogs within the habitat mosaic of the Wadden Sea coast are insufficiently known (but see Meisner et al. 2014 for a preliminary study with 3 tagged foxes along the coast of south Denmark). Therefore, we investigated how foxes and racoon dogs utilised the coastal zone of the Wadden Sea, including the vast saltmarsh areas behind the sea dyke and the numerous adjacent conservation polders and the intensively farmed landscape. The aim of this study was to gather basic information on the spatio-temporal patterns and habitat use of both species to facilitate recommendations for upcoming conservation management plans.

\section{Methods}

\section{Study area}

Employing a large-scale study design, foxes and racoon dogs were caught in various places along the Wadden Sea coast in the German federal states of Schleswig-Holstein (north of river Elbe) and Lower Saxony (south of river Elbe), in the direct vicinity of the saltmarshes and nature conservation polders (Fig. 2), which provide breeding sites for various bird species. In Schleswig-Holstein, foxes and racoon dogs were caught in four different sub-areas: (1) the island of Sylt, which has been connected to the mainland via a railway dam since the $1920 \mathrm{~s}$ and which has high numbers of breeding foxes and racoon dogs (yearly hunting bag: about 150 foxes and 60 racoon dogs (B. Fink hunting district Sylt, pers. comm.)) and includes the large conservation polder "Rantum Becken" as an important site for around 250 breeding pairs of 20 birds species, particularly avocets (Recurvirostra avosetta) and black-headed gulls (Chroicocephalus ridibundus) (Walter 2020; Fig. 2a); (2) the peninsula of Nordstrand and the adjacent conservation polder "Beltringharder Koog" (Fig. 2b); (3) the region "Wurster Küste", including a large summer polder system adjacent to the saltmarshes of the Wadden Sea (Fig. 2c); and (4) a polder system in the mouth of the Elbe river (Fig. 2d).

\section{Catching and tagging of foxes and racoon dogs}

Foxes and racoon dogs were caught in live traps along the Wadden Sea coast by hunters year-round. The traps were mainly placed within small passes between two water bodies and consisted of concrete tubes and a dark wooden box where the caught animal was kept until it was treated. All traps were either controlled two times per day by a hunter or were equipped with a remote system raising an alarm via a SIM card when the trap closed (Trapmaster, EPV Electronics, Germany). The traps met EU regulations, and catching permits were provided by the Obere Jagdbehörde Schleswig-Holstein and the National Park Administration of Lower Saxony. Prior to deployment, all individuals were weighed, sexed, aged (adults were differentiated from immatures < 1-year-old based on tooth abrasion) and anaesthetised by intramuscular injection of $0.3-0.5 \mathrm{ml}$ meditomedine (Dormitor $®$; Orion Corporation, Espoo, Finland; injection volume depended on body weight) and kept in a cage until full muscle relaxation. After deployment of the GPS collars (see below), the same volume of Atipamezole (Antisedan®; Orion Corporation, Espoo, Finland) was injected as an antagonist. All animals were released immediately following deployment. Handling of all animals was in accordance with the permission provided by Ministerium für Energiewende, Landwirtschaft, Umwelt, Natur und Digitalisierung (MELUND) and by Niedersächsisches Landesamt für Verbraucherschutz und Lebensmittelsicherheit (LAVES).

\section{GPS collars}

We used GPS collars from three different companies. (1) "1Cheavy" collars (weighing $190 \mathrm{~g}$ ) were obtained from e-obs GmbH (Grünwald, Germany). These collars stored all data until they were transferred to a base station via a VHF connection. The device schedule was informed by an accelerometer, i.e. devices adopted a low-resolution logging interval when the animal was resting (Brown et al. 2012). This feature enabled us to use the data to compute activity budgets for the foxes (see below). The five e-obs devices used were only 


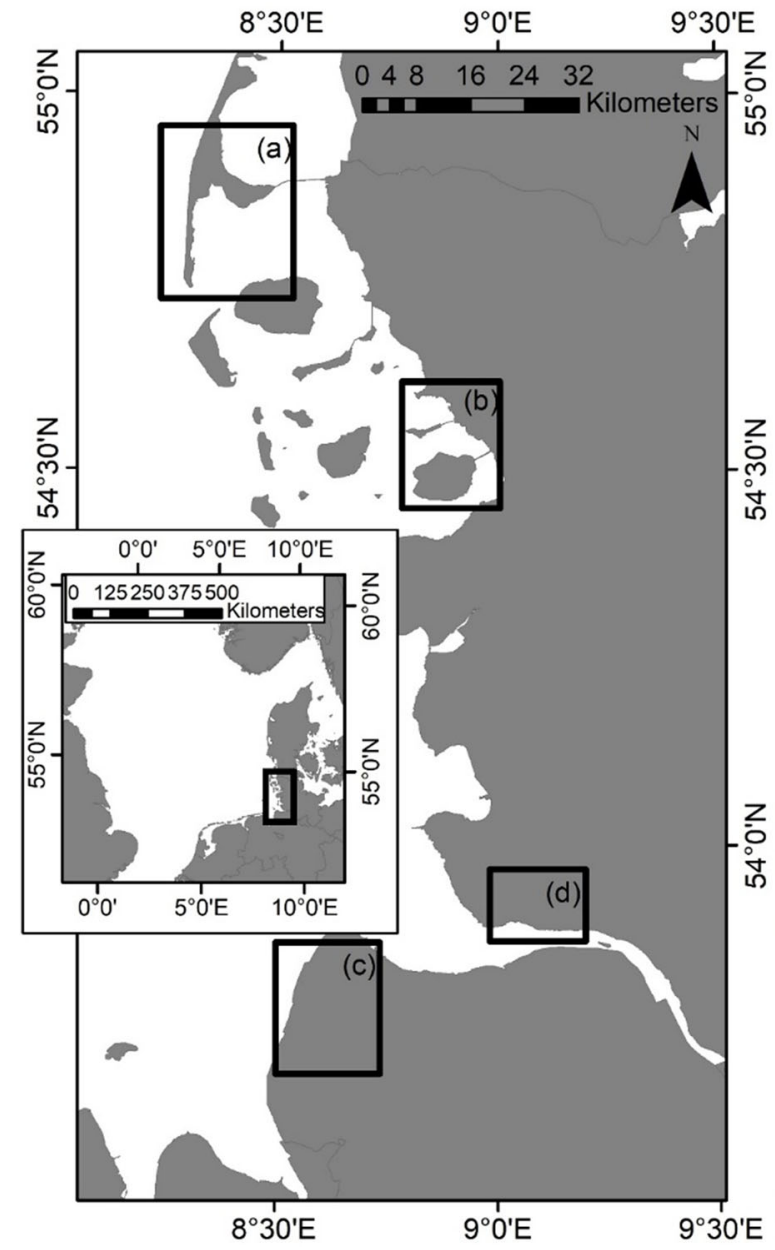

Fig. 2 Study area. Large-scale map: location of study area in Middle Europe; bold rectangle in large-scale map: study area along the eastern Wadden Sea coast including four sub-areas where foxes and racoon dogs were caught. a) Island of Sylt with the conservation polder Rantum Becken; (b) peninsula of Nordstrand adjacent to the conservation polder

applied for foxes (two immature females, one immature male, two adult males; Table 1). (2) "Tellus Ultra Light" collars (weighing $220 \mathrm{~g}$ ) obtained from Followit (Lindesberg, Sweden) were equipped with a GSM module and transferred all recorded data via a mobile phone network to a data server after a minimum of eight logs were recorded. (3) "Felis" collars (weighing $77 \mathrm{~g}$ ) by Ecotone Telemetry (Sopot, Poland) also had a GSM module that allowed about half of the dataset to be transferred to a server via a mobile phone network, while the other half of the recorded data was stored on the collar and could be downloaded using a base station positioned within the home range of the equipped animal. Ecotone devices also had a solar panel to recharge the battery.

The logging schedules of all three device types could be reprogrammed via either a GSM network or a VHF connection to a base station. The schedules were thus adjusted to a logging interval of 20 minutes (shortest time intervals) to 6 hours, depending on the battery status and time of year. We aimed to

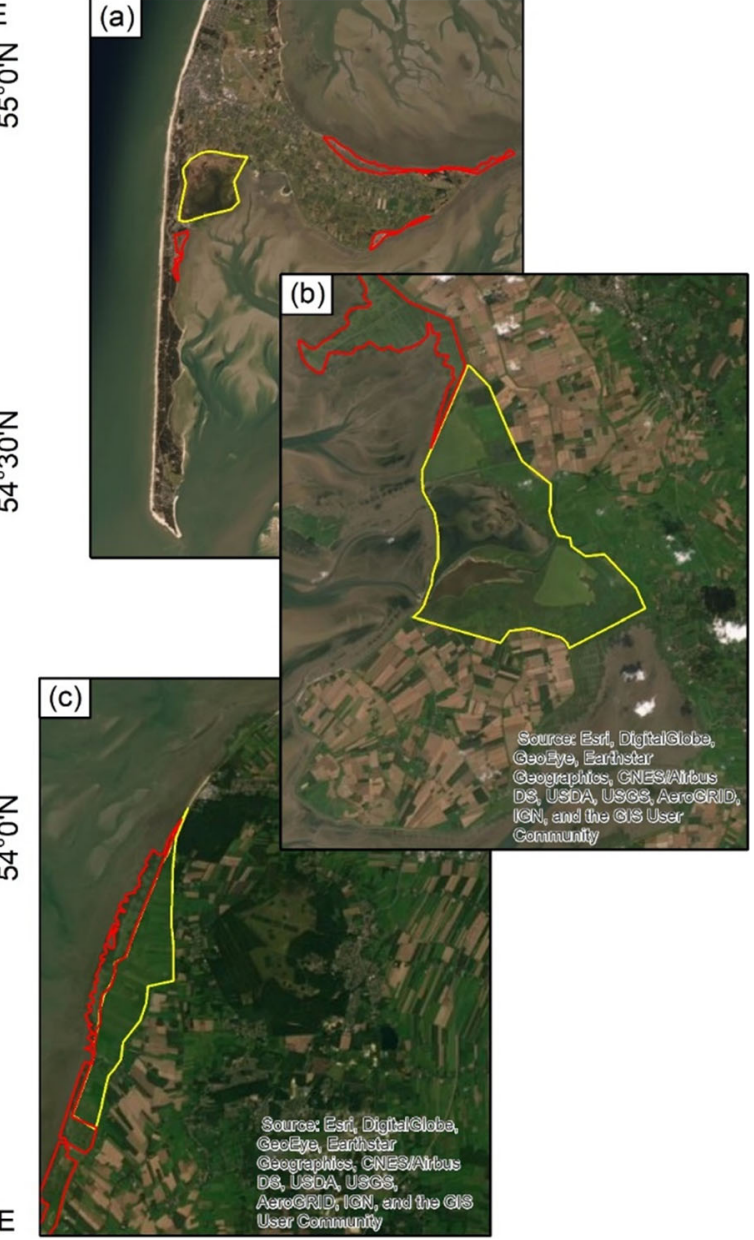

of Beltringharder Koog; (c) Wurster Küste including the summer polder system adjacent to the saltmarshes of the Wadden Sea. Yellow polygons: conservation polders; red polygons: saltmarshes. Sources of satellite images: Esri, DigitalGlobe, GeoEye, Earthstar, Geographics, CNES/Airbus DS, USDA, USGS, AeroGRID, IGN and the GIS User Community

collect most data during the bird-breeding season (March to June) and adjusted the schedule to broader intervals outside the breeding season to conserve battery power. All recorded data were stored on the online portal www.movebank.org.

We equipped 21 foxes, including eight e-obs, seven Followit and six Ecotone devices. However, three of the eight e-obs devices failed to return any data and 18 datasets (11 females, including 3 immatures, and 7 males, including 1 immature) were therefore analysed in this study. Of the 18 datasets, six were generated in the sub-area Beltringharder Koog, one in "Neufeld", seven in Wurster Küste and four on the island of Sylt (Table 1). Five foxes were caught in saltmarshes $(27.8 \%)$, five in conservation polders $(27.8 \%)$ and eight individuals in farmland (44.4\%; see Table 1 for catching location of each individual).

We tagged seven racoon dogs, four with Followit and three with Ecotone devices. However, one Followit collar malfunctioned, and we therefore analysed six datasets in this 


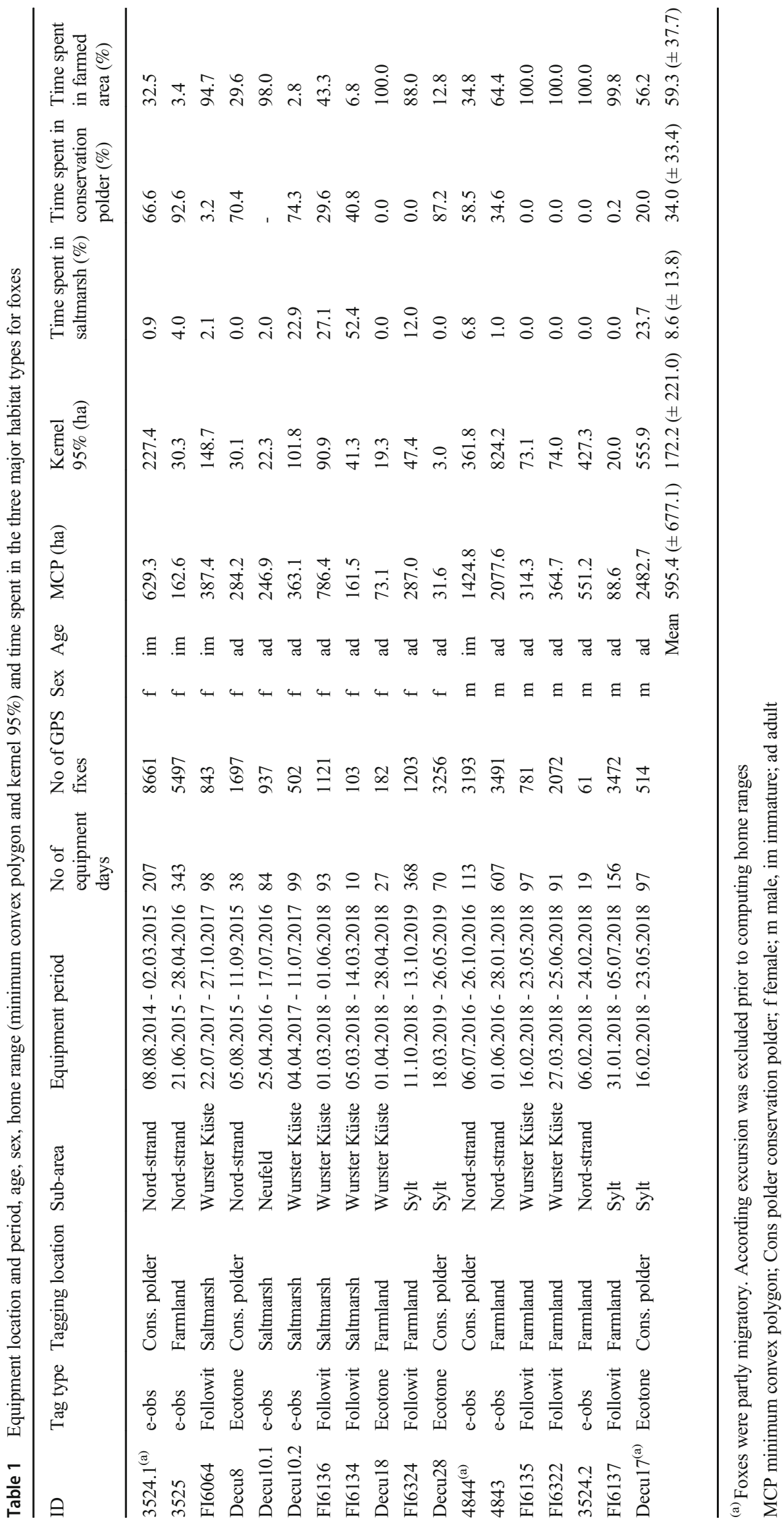


study (three immature males and three adult females). Three datasets were generated in the sub-area Beltringharder Koog, two in Wurster Küste and one on the island of Sylt (Table 2). Two racoon dogs were caught in saltmarshes (33.3\%), three in conservation polders $(50 \%)$ and one in farmland $(16.7 \%)$; see Table 2 for catching location of each individual).

\section{Data analyses and statistics}

Movement patterns for all foxes (except the single fox caught in the Neufeld sub-area) and racoon dogs that returned data were visualised using the Geographical Information System (GIS) ArcGIS 10.3 (Environmental System Research Institute (ESRI) 2011). Home ranges were computed using 95\% fixed kernel distributions (K95) and minimum convex polygons (MCPs100) in the Home Range Tools extension for ArcGIS (Rodgers et al. 2007). The home ranges were computed by excluding excursions (following Burt 1943) which were found in one adult and two immature foxes to explore new territories. We tested for differences in the K95 (response variable) among age and sex (predictors) for foxes using additive linear models (LMs) (Korner-Nievergelt et al. 2015). Because of the small sample size and the uneven sex/age distribution $(n=6)$, we did not perform according tests for racoon dogs. Models were checked for heteroscedasticity by plotting standardised residuals against fitted values. We also visually inspected QQ plots of the residuals to check for normality of the error distribution. No transformation of the response variable was necessary. Finally, we visually inspected the autocorrelation structure of the models using ACF plots. This indicated randomness of the response variable (K95) allowing to test for differences among age and sex using plain LMs.

We computed the proportion of time that a fox or racoon dog, respectively, spent within the three habitat types, "saltmarsh" (i.e. grazed or ungrazed areas between the dyke line and the intertidal flats of the Wadden Sea), "conservation polder" (including the dyke line but excluding water bodies) and "farmed area" (including all types of fields, pastures, bushy areas and small woodlands), based on the aerial images provided by the Nationalpark administration SchleswigHolsteinisches Wattenmeer and satellite imagery provided by the GIS base map. Because this study aimed to analyse habitat use by foxes and racoon dogs at a large spatial scale covering the entire eastern Wadden Sea coast, we did not analyse habitat choice within the fine-scale habitat mosaic (e.g. in relation to different field types or vegetation management), but rather focussed on the relevance of the above three broad-scale habitat types.

We computed a habitat preference index, as suggested by Jacobs (1974), which has previously been used successfully to analyse habitat preference by racoon dogs at a German terrestrial site (Drygala et al. 2008c). We created a resource selection function by determining the overall area of available habitat for each fox and racoon dog, respectively, using the smallest polygon that included all K95 home ranges (Kazmaier et al. 2001; Silva et al. 2009). We then computed the proportions of the three habitat types that fell into the polygons and finally determined the proportion of time that an individual spent within each habitat type. Following Jacobs (1974), the habitat preference was computed using the symmetrical index:

$\left.P_{i}=(U-V) / U+V-2 U V\right)$,

where $U$ was the proportion of habitat used and $V$ was the proportion of available habitat type i. $p$ varied from -1 to +1 , with values close to +1 indicating strong habitat preference, values close to -1 indicating avoidance and values around zero indicating that the respective habitat was used in proportion to its availability.

Differences in preference among the three habitat types were tested using LMs following Tukey's test with Bonferroni correction of the $p$ value (Korner-Nievergelt et al. 2015). Models were checked in the same way as stated above.

All statistical tests were performed using R 3.5.1 (R Core Team 2018).

To determine diurnal activity patterns, all GPS fixes were classified as either "day" (i.e. all daylight hours, including the time of civil twilight) or "night" (i.e. the hours of darkness) using the R-package "suncalc" (Thieurmel and Elmarhraoui 2019). Examples of spatial differences in habitat use between day and night were plotted on a map for three foxes and one racoon dog, to illustrate circadian movement behaviours and space use.

The data generated by the five e-obs devices were finally used to compute activity budgets for the foxes. These devices were controlled by an accelerometer to switch from a high- to a low-resolution logging interval when the animal was resting (Brown et al. 2012). We computed the mean proportion of time $( \pm \mathrm{SD})$ in low-resolution mode for each hour of the day to illustrate the diurnal activity patterns of the foxes.

\section{Results}

\section{Home ranges and spatial patterns}

The 18 foxes showed highly variable home ranges with K95 ranging from 3 ha in an adult female to 824 ha in an adult male (Table 1). The mean K95 home range for all foxes was 172.2 ha, but the standard deviation was large $( \pm 221$ ha; Table 1; Fig. 3). All but three foxes, which performed exploratory excursions (Decu 17 in Fig. 3a, 3524.1 and 3525 in Fig. 3b), showed stable home ranges during the whole tagging period. 
In total, 13 out of 18 individuals had a territory in the direct vicinity of the sea dyke at the edge of the Wadden Sea (Fig. 3). The Wadden Sea islands (except for Sylt) and Halligen were not used by the studied foxes (Fig. 3b), and most individuals spent most of their time in farmed areas and conservation polders. Males had significantly larger K95 home ranges (median: 361.8 ha) than females (median: 41.3 ha; LM: $t=2.8$, degrees of freedom $(\mathrm{df})=15, p=0.013$ ) (Fig. 4a), but there was no significant difference in home range size between age classes (LM: $t=1.6, \mathrm{df}=15, p=0.14$ ) (Fig. 4b). The explained variance of the whole model was $30 \%$. The territories of foxes equipped with GPS collars in the same region showed little overlap (Fig. 5a).

Racoon dogs had smaller home ranges than foxes (mean K95 home range 52.8 ha, with a large standard deviation of 37.3 ha; range 14.5 ha (one adult female) to 129.9 ha (another adult female)) (Table 2). Given the low number of equipment days compared with foxes (Tables 1 and 2), the results for racoon dogs should be interpreted with caution. However, racoon dogs appeared to use similar sites to foxes (Fig. 3), with almost complete overlap of territories with foxes in some cases (Fig. 5b).

\section{Habitat selection and temporal patterns}

Overall, foxes spent most of their time in farmed areas (mean: $59.3 \pm 37.7 \%$ ), followed by conservation polders (mean: 34.0 $\pm 33.4 \%$ ) and saltmarshes (mean: $8.6 \pm 13.8 \%$ ) (Table 1). However, when relating habitat use to habitat availability, the preference index differed significantly among the three habitat classes (ANOVA: $F=8.9$, df $=2, p<0.001$ ), and post-hoc tests indicated that foxes significantly selected conservation polders over farmed areas during day and night and saltmarshes only during the day (Fig. 6a). Furthermore, saltmarsh was selected over farmed areas during the night, but not during the day (Fig. 6a). Significant differences of habitat preferences among day and night within the same habitat type could only be found for conservation polders (i.e. higher preference of conservation polders during the day).

Racoon dogs spent most of their time in conservation polders (mean: $54.3 \pm 42.0 \%$ ) and nearly as much time in farmed areas (mean: $45.2 \pm 42.3 \%$ ), whereas saltmarshes were used very little (mean: $0.5 \pm 0.6 \%$ ) (Table 2). Habitat preference of racoon dogs differed significantly among the three habitat types (ANOVA: $F=97.1, \mathrm{df}=2, p<0.001$ ), and post-hoc tests indicated that racoon dogs significantly preferred conservation polders over farmed areas, both during day and night, and over saltmarshes during day, but not during night (Fig. $6 b)$. Furthermore, there were no significant differences in the use of saltmarsh and farmed areas during the night or during the day (Fig. 6b). Significant differences of habitat preferences between day and night within the same habitat type could be found for conservation polders (i.e. higher preference during 

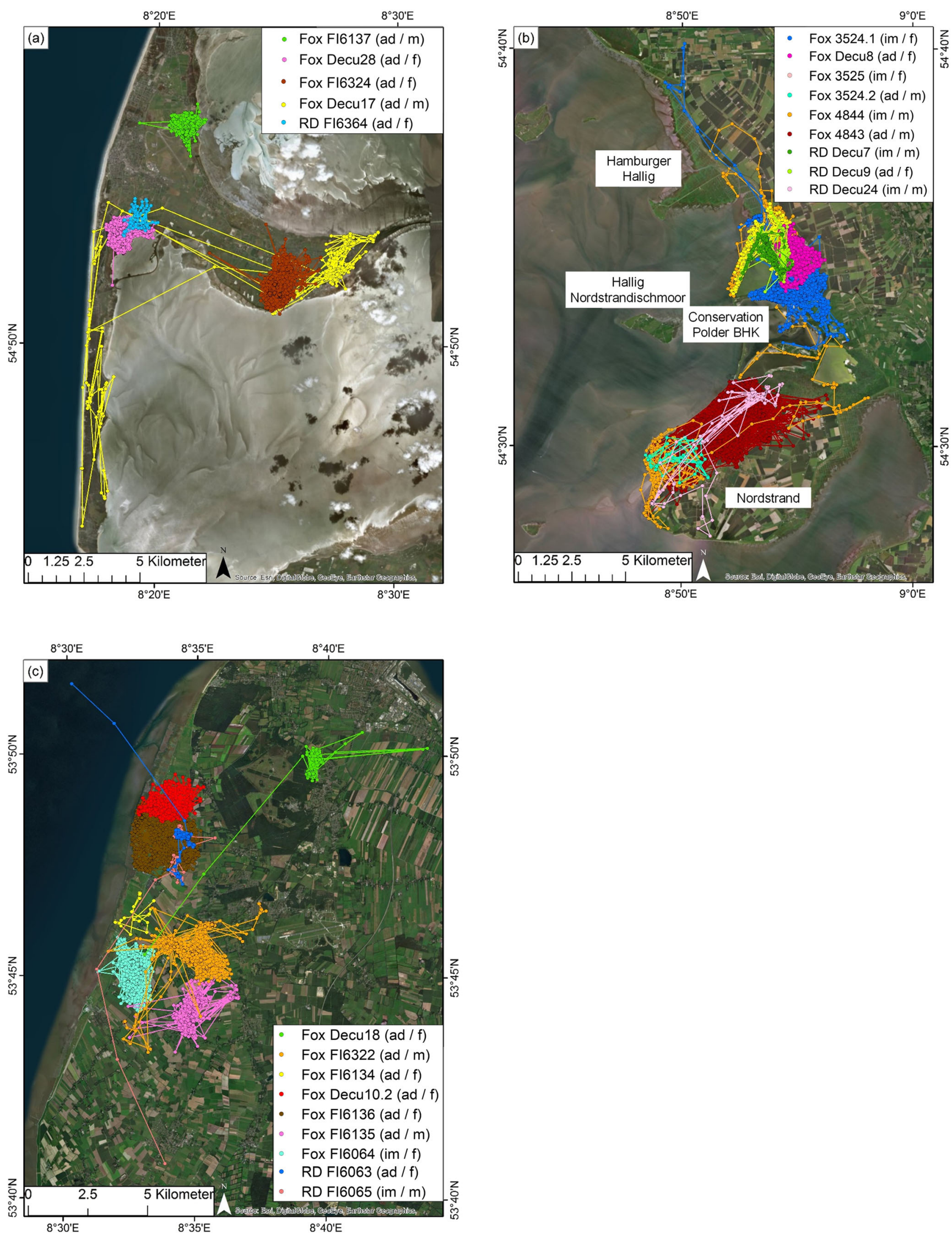

Fig. 3 Spatial patterns of red foxes and racoon dogs in three of the four sub-areas (see Fig. 2 for locations in the overall study area). RD = Racoon dog, ad $=$ adult, $\mathrm{im}=$ immature, $\mathrm{m}=$ male, $\mathrm{f}=$ female, $\mathrm{BHK}=$ Beltringharder Koog. Sources of satellite images: see Fig. 2 

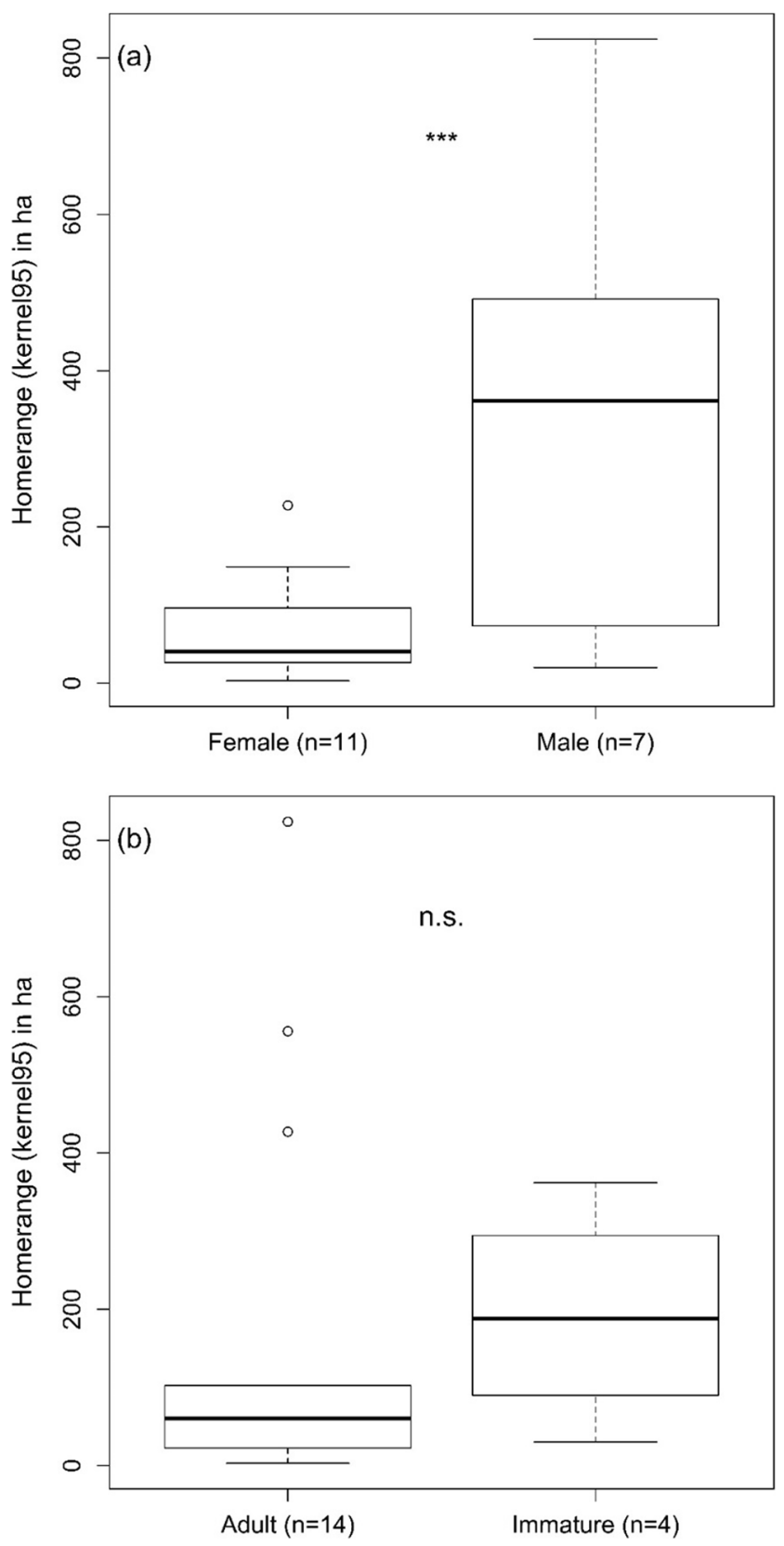

Fig. 4 Kernel 95\% home range sizes of female vs. male (a) and adult vs. immature foxes (b). Bold line: median; box: $25 \%$ confidence interval; dashed line: $95 \%$ confidence interval; open circles: outliers. $* * *=p<$ $0.001 ;$ n.s. $=$ not significant

the day) and for saltmarshes (i.e. higher preference during the night).

Diurnal activity was recorded for five foxes. Foxes were most active during the night and at dusk and dawn (mean proportionate activity time $45-85 \%$ ) (Fig. 7). In contrast, activity clearly decreased around noon, to a mean value of around $20 \%$. All foxes were active for at least some time throughout the daylight hours.

Foxes mainly used open areas during the night but mainly selected sub-areas with high vegetation cover during the day.
For example, female immature fox 3524.1 clearly preferred a corn field with high vegetation cover during the day (yellow polygon in Fig. 8a; only data from 9 August to 1 November 2014 shown), but spent most of its time in the adjacent grazed pasture northwest of the corn field and on the grazed dyke line to the west at night. Female immature fox 3525 mainly used the grazed sea dyke and the pioneer zone of the saltmarsh with low vegetation cover at night, but mainly used a reed bed in the centre of the conservation polder during the day (Fig. 8b; data from the whole equipment period 21 June 2015 to 28 May 2016 shown). Female adult fox Decu10.2 mainly used an ungrazed part of the summer polder during the day (yellow polygon in Fig. 8c) and the grazed part during the night (data from the whole equipment period 4 April to 17 June 2017 shown).

Similar spatio-temporal patterns were found for racoon dogs. For example, racoon dog FI6364 made excursions to the open farmland area and the dyke line separating the conservation polder Rantum Becken from the farmed area at night, but spent most of the daylight hours in either the reed beds in the conservation polder or in dense shrub areas just north of the conservation polder (Fig. 8d; only data from 3 October to 31 December 2019 shown).

\section{Discussion}

\section{Territories and home ranges}

All foxes tagged simultaneously in our study site showed distinct intraspecific avoidance behaviour with exclusive territories, in accordance with the behaviour of foxes elsewhere (e.g. Coman et al. 1991). Carter et al. (2012) stated that there was greater home range overlap between sub-adults than between adult foxes, especially at the cores of their home ranges. The same was found for foxes at an inland site in Germany, close to Berlin (Fiderer et al. 2019), and this was confirmed in the current study.

A review of nine previous studies presenting K95 home range sizes for European red foxes in a variety of landscapes (mainly urban areas and open land) derived a mean size of 131.1 ha (Fiderer et al. 2019). The overall mean of 172.2 ha in the present study would have ranked as the third highest value among these nine studies, indicating that the home ranges of foxes along the Wadden Sea were relatively large. To the best of our knowledge, no previous study has been conducted at a similar coastal site, with only two studies in coastal areas. A study of 24 foxes in an area of sand dunes north of The Hague reported a K95 home range size of 107.5 ha (Dekker et al. 2001), which was significantly smaller than that in the current study. In contrast, another study by Meisner et al. (2014) of three foxes in a coastal polder system found an adaptive K95 home range of 314 ha, which was about twice as large as that 

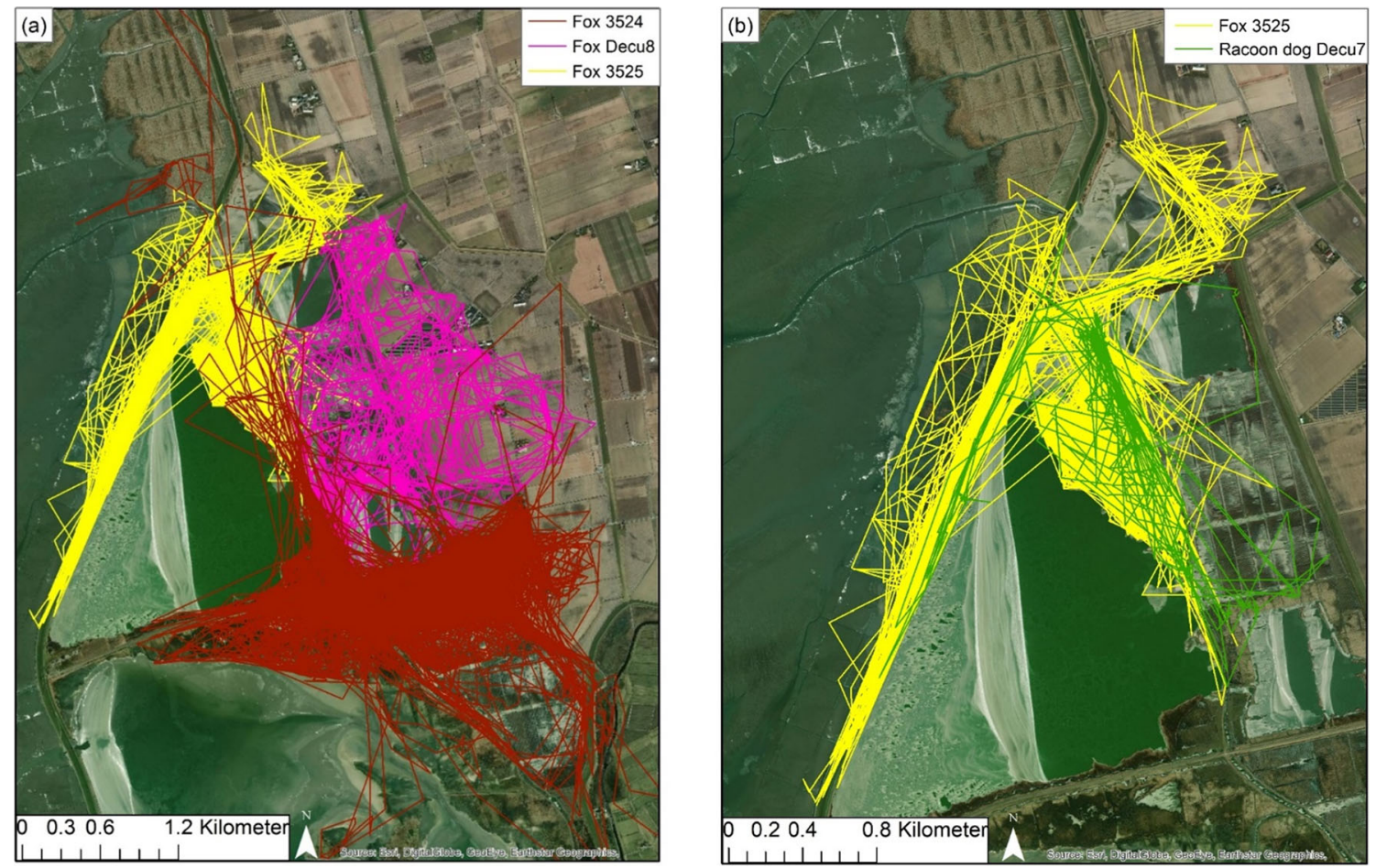

Fig. 5 Examples of spatial overlap among three fox territories (a) and between one fox and one racoon dog territory (b). Sources of satellite images: see Fig. 2

in our study; however, comparisons should be made with care because of the use of different kernel methods and the low sample size $(n=3)$.

The home ranges of racoon dogs in our study were very small and, on average, only about a quarter the size of those of foxes. However, a study at an inland site in northeastern Germany found considerably larger home ranges (i.e. 382 ha for females and 352 ha for males; Drygala et al. 2008a), and a previous study comparing the home ranges of foxes and racoon dogs showed similar average home range sizes in both species (Drygala and Zoller 2013). Given that racoon dogs have smaller home ranges during the cubbing season and after birth (Drygala et al. 2008b), the low values found in our study may have been caused by the small sample size and the comparatively short tagging period for most of the racoon dogs. Our sample size was also too small to draw any conclusions about intraspecific overlap of territories among racoon dogs. However, a radio-tagging study of more individuals at an inland site in Germany suggested that racoon dogs did not have exclusive territories (Drygala et al. 2008a).

Foxes are known to use linear (anthropogenic) structures such as roads and forest edges, as well as settlements (Silva et al. 2009; Janko et al. 2011; Towerton et al. 2016; Bischof et al. 2018), which could explain why many individuals in the current study travelled along the sea dykes or old inland dyke lines separating the conservation polders from the farmed mainland areas. Furthermore, the preference of linear structures might explain why some foxes (though not recorded in our study) might make use of dams connecting islands or
Halligen to the mainland (Schiffler et al. 2018). The remains of dead birds or other animals along the tide line on linear dykes and dams connecting islands and Halligen to the mainland may also increase their use by red foxes, similar to their utilisation of roads to feed on animal carcasses hit by cars (Silva et al. 2009). Foxes along the Wadden Sea coast have been documented to feed on seal carcasses ( $T$. Rosenberger, Seal Station Friedrichskoog, pers. comm.). To the best of our knowledge, there are currently no data on the use of linear structures by racoon dogs; however, this study now suggests that at least some racoon dogs may also use such linear structures, similar to foxes.

Previous studies in Australia and Europe found no significant differences in the home ranges of male and female red foxes (Meek and Saunders 2000; Drygala and Zoller 2013). This contradicts the results of the present study, which found significantly larger home ranges in males compared with females. However, given that male foxes might share their home range with several vixens (e.g. Reynolds and Tapper 1995), larger home ranges in males can be expected. Although we caught the foxes year-round, most females were tracked during the cubbing season, and it is possible that female foxes restricted their activity to areas close to the den during this period and thus had smaller home ranges. However, in most cases, the overall telemetry period for females was longer than the cubbing season, suggesting that female foxes did indeed have smaller home ranges than males.

Drygala and Zoller (2013) found that female racoon dogs had larger K95 home ranges than female foxes, while male 
Fig. 6 Habitat preference of foxes (a) and racoon dogs (b). For explanation of the box plots, see Fig. 4. $*=p<0.05, * *=p<0.01$, $* * *=p<0.001 ;$ n.s. $=$ not significant
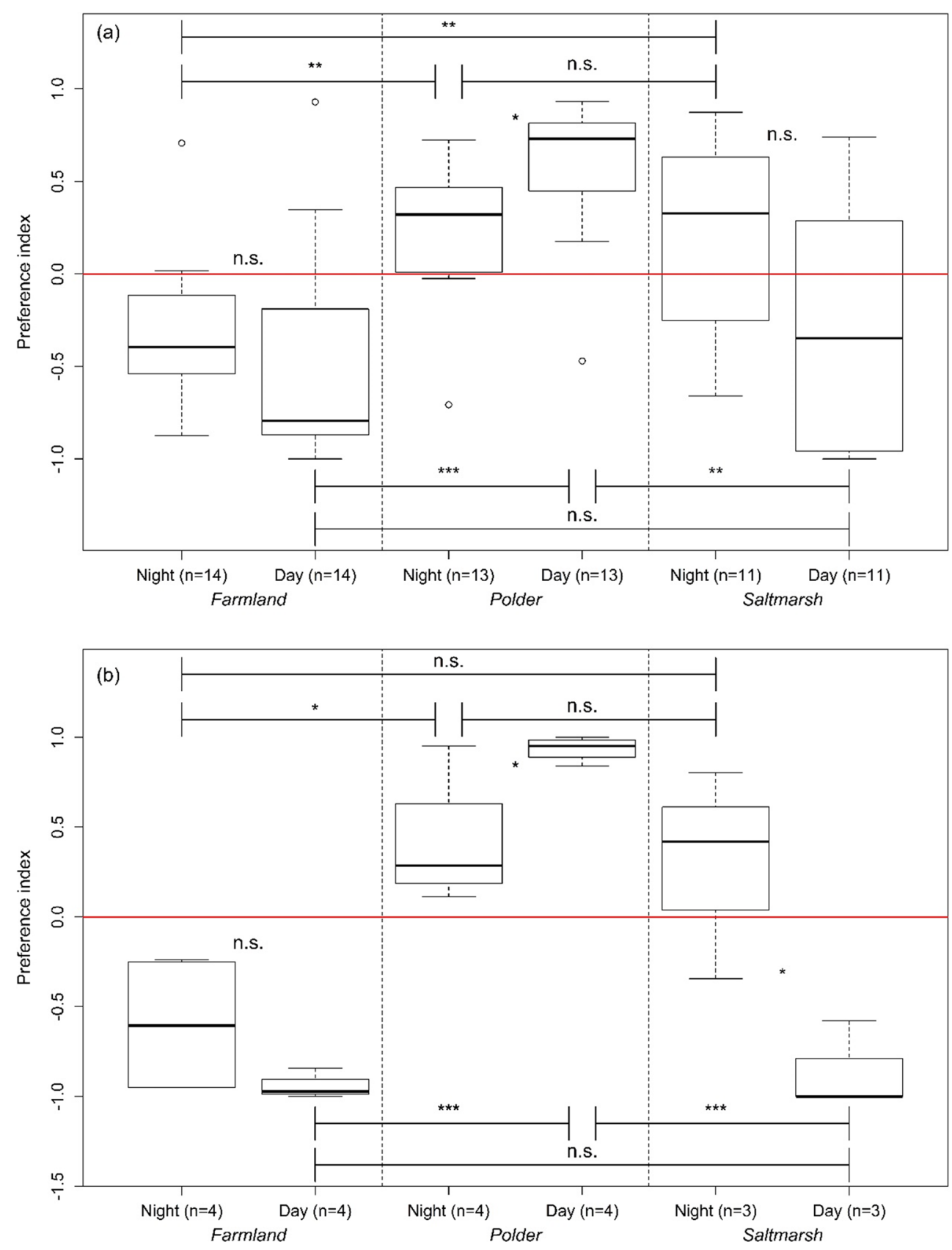

racoon dogs had smaller home ranges than male foxes. Although our sample size of racoon dogs was too small to differentiate between the sexes, we found clear indications that racoon dogs had smaller home ranges than foxes of either sex.

Former studies also found similar dispersal distances for immature male and female racoon dogs (e.g. Drygala et al. 2010). Given the biased sex and age distribution of racoon dogs in our study, we were not able to show similar patterns.

Or findings indicated that the home ranges of racoon dogs and foxes overlapped with no strong interaction or competition between the two species. This was supported by a study in northeast Germany, which showed a low degree of interaction between these two species (Drygala and Zoller 2013).

\section{Temporal patterns}

Our study clearly demonstrated that foxes showed a crepuscular and nocturnal activity peak. However, in contrast to previous studies (e.g. Meek and Saunders 2000; Carter et al. 2012), all individuals in this study also showed high levels of diurnal activity, particularly in areas of dense vegetation. Our findings suggest that foxes took the opportunities to hide in 
Fig. 7 Diurnal activity patterns of five foxes. Bars represent mean proportions of activity; error bars depict standard deviation

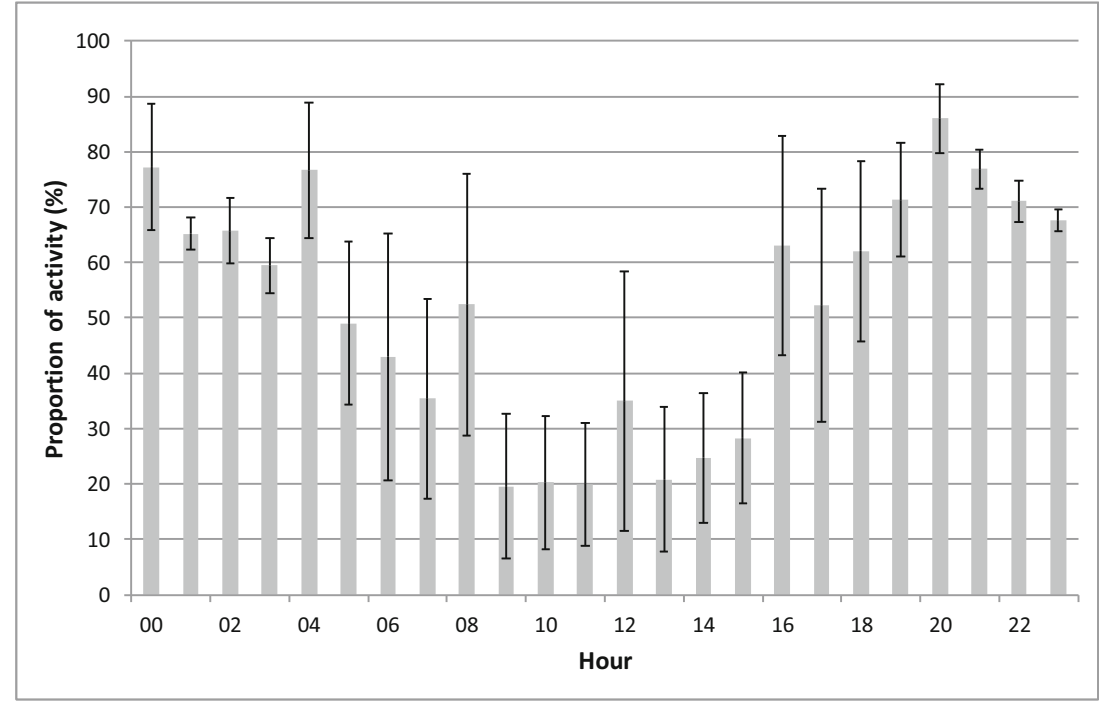

the nature conservation polders and ungrazed saltmarshes that offer high vegetation structure throughout the year.

Although our sample size of racoon dogs was too small to draw any conclusions regarding their hourly circadian activity budget, our data clearly suggest that racoon dogs were active almost exclusively at night and spent the daylight hours hidden in dense vegetation (mainly in conservation polders). The more open saltmarshes were used significantly more during the night. This matches the findings for racoon dogs equipped with VHF telemetry devices in northeastern Germany, where the authors found that $87 \%$ of activity occurred at night (Zoller and Drygala 2013). However, in contrast to former studies that found opportunistic use of different habitat types by racoon dogs with no clear temporal pattern (Drygala et al. 2008c), our results clearly suggest that the tagged individuals spent most of their time (particularly during daytime) preferably within conservation polders with abundant reed beds that offer dense vegetation that racoon dogs are known to use as shelter against cold, predation and human disturbance (Kowalczyk and Zalewski 2011).

\section{Habitat use along the Wadden Sea coast}

Given that foxes and racoon dogs showed a limited home range, the habitat choice of both species needs to be interpreted against the background of the catching location. However, we were able to equip similar numbers of both species across all three habitat types and additionally all individuals were caught in direct vicinity of all three habitat types. Therefore, our study design should provide correct results on habitat preferences.

The current results showed that both foxes and racoon dogs significantly preferred conservation polders adjacent to the coast, compared with saltmarshes and farmland. Anthropogenic activities and management measures in these conservation areas are usually low and predators can therefore hide easily in the vast reed beds, while these conservation sites also usually include high densities of ground-nesting birds (e.g. Bruns et al. 2001), potentially explaining the importance of these areas for both study species, particularly during the daylight hours. According to studies using nest cameras (Salewski and Schmidt 2020), red foxes were responsible for $46 \%$ and racoon dogs for $28 \%$ of the predation events of black-tailed godwits (Limosa limosa) nests in conservation polders along the Wadden Sea coast, whereas polecats (Mustela putorius) were recorded in $18 \%$ and other mammal or bird species only in $<10 \%$ of the cases (Salewski and Schmidt 2019; Salewski et al. 2019).

In a similar study at a mainland site, Fiderer et al. (2019) equipped nine racoons (Procyon lotor) and five foxes over a 22 -month period. They showed that racoon activity mostly overlapped with reed and swamp areas, indicating high overlap with waterfowl-breeding sites in reed beds, while foxes preferred woodlands, with little overlap in home ranges between foxes and racoons. Fiderer et al. (2019) suggested that foxes exerted high predation pressure on ground-nesting birds in grassland close to woodland. In the absence of woodlands in our study area, the core home ranges of many individuals in our study were in reed areas within nature conservation polders, and the tagged foxes appeared to prefer this habitat type. A preference of foxes for dense vegetation such as shrubs, forests or reed beds has been found in other studies at different sites in the northern hemisphere (e.g. van Etten et al. 2007; Fiderer et al. 2019).

The management schemes (grazing by cattle or mowing) and vegetation structures of conservation polders and saltmarshes are not easily compared. However, since a moderately high proportion of mainland saltmarshes are no longer grazed or mowed (Esselink et al. 2017), their vegetation structure (in terms of hiding possibilities for foxes and racoon 

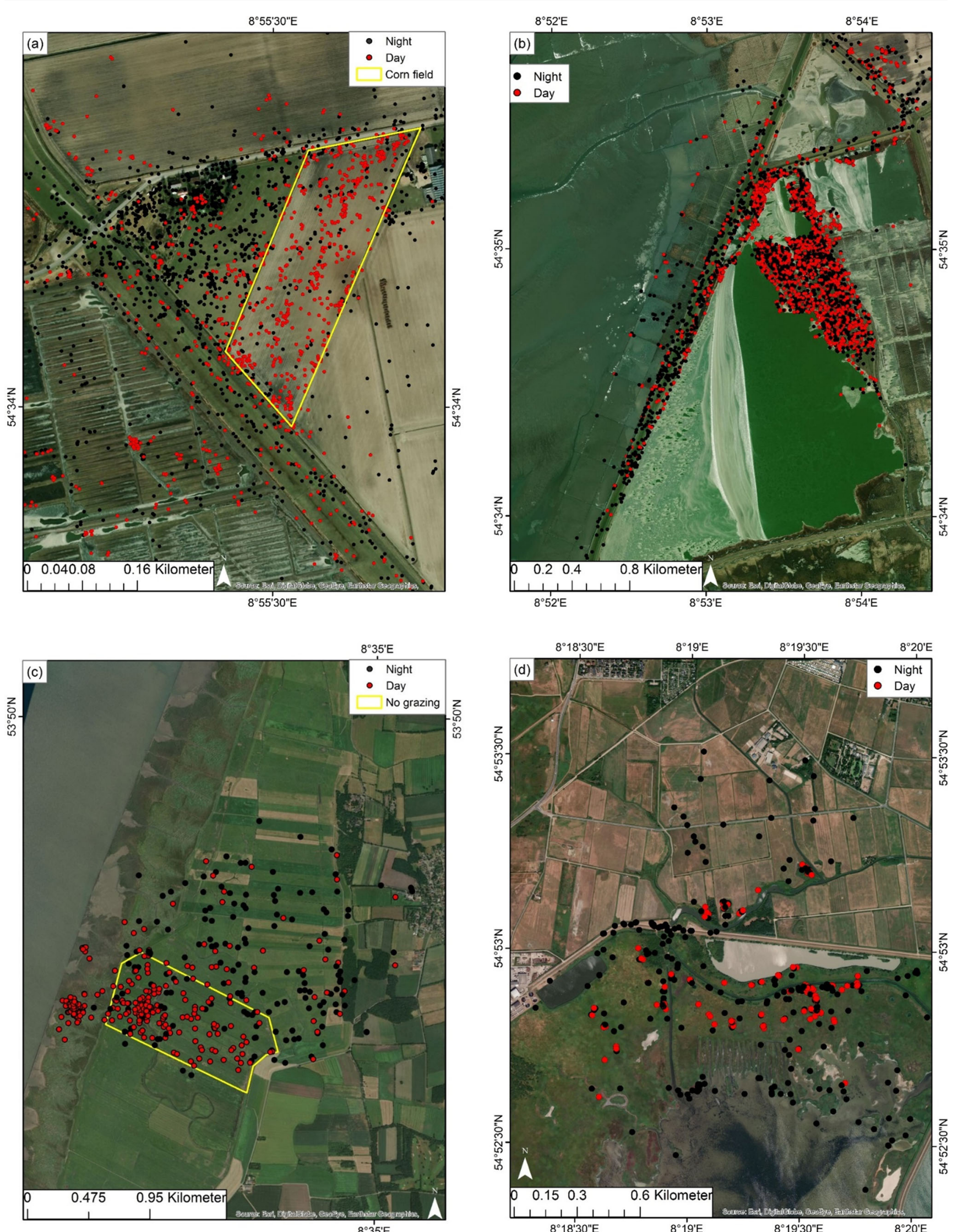

Fig. 8 Examples of spatio-temporal activity patterns of three foxes $(\mathbf{a}-\mathbf{c})$ and one racoon dog (d) (using data from 3 October 2019 to 31 December 2019 ). Yellow polygon in (a): corn field (data from 9 August to 1 November 2014); yellow polygon in (c): ungrazed area in summer polder. Sources of satellite images: see Fig. 2 
dogs) in some respects resembles that in conservation polders. It is therefore surprising that our study did not show similarly high preferences of either foxes or racoon dogs for these two habitat types. However, there was a significant indication that foxes preferred saltmarshes over farmlands during the night (suggesting better foraging options in saltmarshes during this time), whereas racoon dogs showed similar preferences for these two habitat types during day and night.

Whether foxes and racoon dogs deliberately select areas with high bird densities remains to be proven, although a previous study found no evidence to support such a relationship (Meisner et al. 2014). While foxes were found to significantly impact bird populations, the role of racoon dogs as nest predators seems to be strongly site-specific. While studies from northern Europe found only low predation pressure on ground-breeding birds (Opermanis et al. 2001; Kauhala 2004; see review in Kauhala and Kowalczyk 2011), a recent study carried out in one of our study sites using nest cameras revealed that red foxes and racoon dogs were the most significant nest predators in breeding areas of blacktailed godwits suggesting that both species might prefer areas with high nest densities (Salewski and Schmidt 2019). Future studies conducted at smaller spatial scales are needed to shed light on the link between numbers of breeding birds and the spatial activity patterns of the two predators. However, the availability of other prey resources, such as mice, might help to explain the habitat preferences of foxes and racoon dogs. Previous studies have shown the importance of small rodents in the diets of both species, together with cereals and fruits for racoon dogs (Kauhala et al. 1993; Dell'Arte et al. 2007; Sutor et al. 2010; Elmeros et al. 2018). Although no monitoring data are available, the availability of such prey types is likely to be low in saltmarshes (as a consequence of regular inundation during storm tides, which will not be tolerated by many rodents) compared with conservation polders and farmland areas, particularly outside the breeding season.

Nevertheless, our results suggest that areas within the coastal habitat mosaic that offer high vegetation cover are used over-proportionally by both foxes and racoon dogs, particularly at daytime (see examples for corn field and ungrazed pasture within the summer polder in Fig. 8c).

\section{Conclusions}

This study clearly shows that foxes and racoon dogs use the mosaic of the coastal landscape in a sophisticated way. Home ranges of foxes along the Wadden Sea coast were among the largest recorded in Europe, so far. Overlap of home ranges of the two species indicates that a co-existence in the same territories is possible. The results highlight the important role of conservation polders, including large reed beds, for foxes and racoon dogs particularly during daytime. These are also the sites where many losses among ground-breeding birds by the two species were recorded (Salewski and Schmidt 2019; Salewski et al. 2019). Although most foxes along the coast seem to prefer habitat types other than saltmarshes (where the highest numbers of ground-nesting birds can be found; Koffijberg et al. 2017), some foxes also showed a preference for saltmarshes particularly during the night. While direct effects of foxes and racoon dogs on ground-breeding birds within this habitat type remain to be proven by systematically designed studies (e.g. by using nest cameras), the results of our study show that both predators were using linear structures such as flood lines in the tidal area, along dykes and dams suggesting that the tagged individuals made use of carcasses. The attraction effect by carcasses along dams can play an important role for individual predators entering areas with high densities of breeding birds, such as saltmarshes on islands and Halligen (Schiffler et al. 2018), which could have important effects on the populations of ground-nesting birds (e.g. Mason et al. 2018), with potentially severe effects on breeding success (Salewski and Schmidt 2019).

Although the current study was designed to unravel the different importance of three major habitat types along the Wadden Sea coast for foxes and racoon dogs using a broadscale approach, we could clearly show that diurnal activity patters of foxes and racoon dogs also differed on a small spatial scale (i.e. use of areas with dense vegetation during the day and areas with short vegetation during the night). Future work may now focus on exploring the habitat selection patterns at finer spatial scales, e.g. to determine the preferred vegetation types within conservation polders, crop types in the farmed areas and management regimes within the saltmarsh areas.

Acknowledgements We thank the many hunters who provided live traps to catch foxes and racoon dogs, particularly Holger Krön, Frank Penner, Manfred Ückermann and Dominic Wauer, as well as Oliver Granke from LifeLimosa. Kai Borkenhagen, Leonie Enners, Daniela Koch and Sabine Müller and the veterinarians Henrike Seibel and Thomas and Christine Montag helped with catching and handling the caught animals. We thank Sue Furness for support with the English.

Funding Open Access funding enabled and organized by Projekt DEAL. The study was funded by the Schleswig-Holstein Agency for Coastal Defense, National Park and Marine Conservation-National Park Authority and Nationalpark Administration Niedersachsen, Wilhelmshaven.

Data Availability Tracking data of foxes and racoon dogs are archived at Movebank (https://www.movebank.org).

\section{Declarations}

Ethics approval Permission to catch and equip foxes and racoon dogs with GPS collars in the federal state of Schleswig-Holstein was provided 
by the Federal Ministry of Energy Transition, Agriculture, Environment, Nature and Digitalization (MELUND; file numbers V 312-7224.121-37 (42-3/13) and V 241-35852/2017(88-7/17)) and in the federal state of Niedersachsen by the Lower Saxony State Office for Consumer Protection and Food Safety (LAVES; file number 33.19-42502-04-17/ 2699).

Conflicts of interest/competing interests The authors declare no conflict of interests and no competing interest.

Open Access This article is licensed under a Creative Commons Attribution 4.0 International License, which permits use, sharing, adaptation, distribution and reproduction in any medium or format, as long as you give appropriate credit to the original author(s) and the source, provide a link to the Creative Commons licence, and indicate if changes were made. The images or other third party material in this article are included in the article's Creative Commons licence, unless indicated otherwise in a credit line to the material. If material is not included in the article's Creative Commons licence and your intended use is not permitted by statutory regulation or exceeds the permitted use, you will need to obtain permission directly from the copyright holder. To view a copy of this licence, visit http://creativecommons.org/licenses/by/4.0/.

\section{References}

Bischof R, Gjevestad JGO, Ordiz A, Eldegard K, Milleret C (2018) High frequency GPS bursts and path-level analysis reveal linear feature tracking by red foxes. Sci Rep 9:8849. https://doi.org/10.1038/ s41598-019-45150-x

Brown DD, LaPoint S, Kays R, Heidrich W, Kümmeth F, Wikelski M (2012) Accelarometer-informed GPS telemetry: reducing the tradeoff between resolution and longevity. Wildl Soc Bull 36:139-146

Bruns HA, Hötker H, Christiansen J, Hälterlein B, Petersen-Andresen W (2001) Brutbestände und Bruterfolg von Wiesenvögeln im Beltringharder Koog (Nordfreisland) in Abhängigkeit von Sukzession, Beweidung, Wasserständen und Prädatoren. Corax 18:67-80

Burt WH (1943) Territoriality and home range concepts as applied to mammals. J Mammal 24:346-352

Carter A, Luck GW, McDonald SP (2012) Ecology of the red fox (Vulpes vulpes) in an agricultural landscape. 2. Home range and movements. Aust Mamm 34:175-187

Cimiotti D, Klinner-Hötker (2019) Schutzkonzept Austernfischer in Schleswig-Holstein - Untersuchungen 2019. Bericht für das Ministerium für Energiewende. Landwirtschaft, Umwelt, Natur und Digitalisierung des Landes Schleswig-Holstein https:// bergenhusen.nabu.de/imperia/md/nabu/images/nabu/einrichtungen/ bergenhusen/projekte/austernfischer/bericht_austernfischer_2019. pdf. Accessed Dec 2020

Coman BJ, Robinson J, Beaumont C (1991) Home range, dispersal and density of red foxes (Vulpes vulpes L.) in central Victoria. Wildl Res 18:215-223

Dekker JJA, Stein A, Heitkönig MA (2001) A spatial analysis of a population of red fox (Vulpes vulpes) in the Dutch coastal dune area. J Zool Lond 255:505-510

Dell'Arte GL, Laaksonen T, Norrdahl K, Korpimaki E (2007) Variation in the diet composition of a generalist predator, the red fox, in relation to season and density of main prey. Acta Oecol-Intern J Ecol 31: 276-281

Drost B-D (2013) Fuchs-Alarm auf Habel. Seevögel 34:77
Drygala F, Zoller H (2013) Spatial use and interaction of the invasive raccoon dog and the native red fox in Central Europe: competition or coexistence? Eur J Wildl Res 59:683-691

Drygala F, Stier N, Zoller H, Mix HM, Bögelsack K, Roth M (2008a) Spatial organisiation and intra-specific relationship of the raccoon dog Nyctereutes provyonoides in Central Europe. Wildl Biol 14: 457-466

Drygala F, Zoller H, Stier N, Mix H, Roth M (2008b) Ranging and parental care of the raccoon dog Nyctereutes procyonoides during pup rearing. Acta Theriol 53:111-119

Drygala F, Stier N, Zoller H, Boegelsack K, Mix HM, Roth M (2008c) Habitat use of the raccoon dog (Nyctereutes procyonoides) in northeastern Germany. Mamm Biol 73:371-378

Drygala F, Zoller H, Stier N, Roth M (2010) Dispersal of the raccoon dog Nyctereutes procyonoides into a newly invaded area in Central Europe. Wildl Biol 16:150-161

Elmeros M, Mikkelsen DMG, Nørgaard LS, Pertoldi C, Jensen TH, Chriél M (2018) The diet of feral raccoon dog (Nyctereutes procyonoides) and native badger (Meles meles) and red fox (Vulpes vulpes) in Denmark. Mamm Res 63:405-413

Environmental Systems Research Institute (ESRI) (2011) ArcGIS v. 10.3 ESRI, Redlands, California

Fiderer C, Göttert T, Zeller (2019) Spatial interrelations between raccoons (Procyon lotor), red foxes (Vulpes vulpes), and ground-nesting birds in a Special Protection Area of Germany. Eur J Wildl Res 65:14. https://doi.org/10.1007/s10344-018-1249-z

Gołdyn B, Hromada M, Surmacki A, Tryjanowski (2003) Habitat use and diet of the red fox Vulpes vulpes in an agricultural landscape in Poland. Z Jagdwiss 49:1-10

Heidemann G (1975) Erster Marderhund (Nyctereutes procyonides Gray, 1834) in Schleswig-Holstein. Z Jagdwiss 21:79-80

Hofstede JLA (2019) On the feasibility of managed retreat in the Wadden Sea of Schleswig-Holstein. J Coast Conserv 23:1069-1079

Jacobs J (1974) Quantitative measurements of food selection. A modification of the forage ratio and Ivlev's electivity index. Oecologia 76: 1036-1046

Janko C, Linke S, Romig T, Thoma D, Schröder W, König A (2011) Infection pressure of human alveolar echinococcosis due to village and small town foxes (Vulpes vulpes) living in close proximity to residents. Eur J Wildl Res 57:1033-1042

JMBB - Joint Monitoring Breeding Bird Group (2013) Breeding birds in trouble - Preparation of an action plan for proper management of threatened breeding birds in the Wadden Sea. Workshop report, Common Wadden Sea Secretariat, Wilhelmhaven

Kauhala K (2004) Removal of medium-sized predators and the breeding success of ducks in Finland. Folia Zool 53:367-378

Kauhala K, Ihalainen A (2014) Impact of landscape and habitat diversity on the diversity of diets of two omnivorous carnivores. Acta Theriol 59:1-12

Kauhala K, Kowalczyk R (2011) Invasion of the racoon dog Nyctereutes procyonoides in Europe: History of colonization, features behind its success, and threats to native fauna. Curr Zool 57:584-598

Kauhala K, Kaunisto M, Helle E (1993) Diet of the raccoon dog, Nyctereutes procyonoides, in Finland. J Mamm Biol 58:129-136

Kazmaier RE, Hellgren C, Ruthven DC (2001) Habitat selection by the Texas tortoise in a managed thornscrub ecosystem. J Wildl Manag 65:653-660

Koffijberg K, Laursen K, Hälterlein B, Reichert G, Frikke F, Soldaat L (2015) Trends of breeding birds in the Wadden Sea 1991 - 2013. Wadden Sea Ecosystem No. 35. Common Wadden Sea Secretariat, Joint Monitoring Group of Breeding Birds in the Wadden Sea, Wilhelmshaven, Germany. https://www.waddensea-worldheritage. org/resources/ecosystem-35-trends-breeding-birds Last accessed 12.12.2019

Koffijberg K, Frikke J, Hälterlein B, Laursen K, Reichert G, Soldaat L (2017) Breeding birds. In: Kloepper S et al., (eds) Wadden Sea 
Quality Status Report 2017. Common Wadden Sea Secretariat, Wilhelmshaven, Germany. https://qsr.waddensea-worldheritage. org/reports/breeding-birds Last accessed 12.12.2019

Korner-Nievergelt F, Roth T, von Felten S, Guélat J, Almasi B, KornerNievergelt P (2015) Bayesian data analysis in ecology using linear models with R, BUGS and Stan. Elsevier, London

Kowalczyk R, Zalewski A (2011) Adaptation to cold and predation shelter use by invasive raccoon dogs Nyctereutes procyonoides in Białowieża Primeval Forest (Poland). Eur J Wildl Res 57:133-142

Leyrer J, Frikke J, Hälterlein B, Koffijberg K, Körber P, Reichert G (2019) Managing predation risk for breeding birds in the Wadden Sea. Results from a workshop in Tönning, Schleswig-Holstein, 7-8 March 2017. Wadden Sea Ecosystem No. 38. Common Wadden Sea Secretariat, Joint Monitoring Breeding Bird Group (JMBB) in the Wadden Sea, Wilhelmshaven, Germany. https://www. waddensea-worldheritage.org/sites/default/files/2019 Ecosystem 38 predation\%20management.pdf. Accessed Nov 2020

Long PR, Székely T, Kerhsaw M, O’Connell M (2007) Ecological factors and human threats both drive wildfowl population declines. Anim Conserv 10:183-191

Mason LR, Smart J, Drewitt AL (2018) Tracking day and night provides insights into the relative importance of different wader chick predators. Ibis $160: 71-88$

Meek PD, Saunders G (2000) Home range and movement of foxes (Vulpes vulpes) in coastal New South Wales, Australia. Wildl Res 27:663-668

Meisner K, Sunde P, Clausen KK, Causen P, Fælled CC, Hoelgaard M (2014) Foraging ecology and spatial behaviour of the red fox (Vulpes vulpes) in a wet grassland ecosystem. Acta Theriol 59: 377-389

MELUND-Ministerium für Energiewende, Landwirtschaft, Umwelt, Natur und Digitalisierung des Landes Schleswig-Holstein (2018). Jahresbericht 2018 zur biologischen Vielfalt - Jagd und Artenschutz (2018) https://www.schleswig-holstein.de/DE/ Fachinhalte/A/artenschutz/Downloads/Jahresbericht_zur biologischen Vielfalt 2018.pdf? blob=publicationFile\&v $=\overline{1}$ Last accessed 12.12.2019

Nowak E (1973) Ansiedlung und Ausbreitung des Marderhundes (Nyctereutes procyonoides GRAY) in Europa. Beit Jagd Wildf 8: 351-384

Opermanis O, Mednis A, Bauga I (2001) Duck nests and predators: interaction, specialisation and possible management. Wildl Biol 7: $87-96$

OSPAR (2013) OSPAR Common Indicators and Candidate Indicators, Annex 4. Meeting of the OSPAR Commission. Gothenburg, Sweden

R Core Team (2018) R: A Language and Environment for Statistical Computing. R Foundation for Statistical Computing, Vienna, Austria. https://www.R-project.org/ Last accessed 04 ${ }^{\text {th }}$ March 2020

Reynolds JC, Tapper SC (1995) The ecology of the red fox Vulpes vulpes in relation to small game in rural southern England. Wildl Biol 1: 105-119

Rickenbach O, Gruebler MU, Schaub M, Koller A, Naef-Daenzer B, Schifferli L (2011) Exclusion of ground predators improves Northern lapwing Vanellus vanellus chick survival. Ibis 153:531542

Rodgers AR, Carr AP, Beyer HL, Smith L, Kie JG (2007) HRT: home range tools for ArcGIS Ontario ministry of natural resources. Centre for Northern Forest Ecosystem Research, Thunder Bay

Salewski V, Schmidt L (2019) The raccoon dog - an important new nest predator of black-tailed godwit in northern Germany. Wader Study $126: 28-34$
Salewski V, Schmidt L (2020) Nest cameras do not affect nest survival in a meadow-nesting shorebird. Bird Cons Int:1-10. https://doi.org/10. 1017/S0959270920000659

Salewski V, Evers A, Schmidt (2019) Wildkameras ermitteln Verlustursachen von Gelegen der Uferschnepfe (Limosa limosa) Camera traps reveal predators of clutches of the black-tailed godwit (Limsoa limisa). Natur und Landschaft 94:59-65. https://doi.org/10. 17433/2.2019.50153663.59-65

Schiffler M, Lutz K, Schrader S (2018) Planfeststellungsverfahren Wiederherstellung der Sollhöhe des Wattsicherungsdammes Festland - Oland - Langeness. Untersuchungen zum Einfluss von Raubsäugetieren auf die Brutvogelbestände Stand 2018. Biodiversity \& Wildlife Consulting, unpublished report

Schmüser H, Fehlberg U, Graumann S (2019) Enok - heimlicher Eroberer - Populationsentwicklung des Marderhundes in Schleswig-Holstein. Jäger in Schleswig-Holstein 65:12-14

Schwemmer P, Hälterlein B, Geiter O, Günther K, Corman VM, Garthe S (2014) Weather-related winter mortality of Eurasian oystercatchers (Haematopus ostralegus) in the northeastern Wadden Sea. Waterbirds 37:319-330

Silva M, Johnson KM, Opps SB (2009) Habitat use and home range size of red foxes in Prince Edward Island (Canada) based on snowtracking and radio-telemetry data. Cent Eur J Biol 4:229-240

Sutor A (2008) Dispersal of the alien raoon dog Nyctereutes procyonoides in sothern Brandenburg, Germany. Eur J Wildl Res 54:321-326

Sutor A, Kauhala K, Ansorge H (2010) Diet of the raccoon dog Nyctereutes procyonoides - a canid with an opportunistic foraging strategy. Acta Theriol 55:165-176

Thieurmel B, Elmarhraoui A (2019) Package "suncalc". https:/github. com/datastorm-open/suncalc Last accessed 12.12.2019

Thorup O, Koffijberg K (2016) Breeding success in the Wadden Sea 2009-2012 A review. Wadden Sea Ecosystem No. 36. Common Wadden Sea Secretariat, Wilhelmshaven, Germany. https://www. waddensea-worldheritage.org/resources/ecosystem-36-breedingsuccess-wadden-sea-2009-2012 Last accessed 12.12.2019

Towerton AL, Kafanagh RP, Penman TD, Dickman CR (2016) Ranging behavior and movements of the red fox in remnant forest habitats. Wildl Res 43:492-506

Esselink P van Duin WE, Bunje J, Cremer J, Folmer EO, Frikke J, Glahn M, de Groot AV, Hecker N, Hellwig U, Jensen K, Körber P, Petersen J, Stock M (2017) Salt marshes. Kloepper S et al. (eds) In: Wadden Sea Quality Status Report 2017. Common Wadden Sea Secretariat Wilhelmshaven, Germany. https://qsr.waddenseaworldheritage.org/reports/salt-marshes. Last accessed 25.03.2020.

van Etten KW, Wilson KR, Crabtree RL (2007) Habitat use of red foxes in Yellowstone National Park based on snow tracking and telemetry. J Mammal 88:1498-1507

Walter E (2020) Brutbericht aus unseren Schutz- und Zählgebieten im Jahr 2019. Seevögel 41:4-7

Wetlands International (2006) Waterbird Population Estimates, 4th edn. Wageningen, Wetlands International

Williamson L, Hudson M, O'Connell M, Davidson N, Young R, Amano T, Székely T (2013) Areas of high diversity for the world's inlandbreeding waterbirds. Biodivers Conserv 22:1501-1512

Zoller J, Drygala F (2013) Activity patterns of the invasive raccoon dog (Nyctereutes procyonoides) in North East Germany. Folia Zool 62: 290-296

Publisher's note Springer Nature remains neutral with regard to jurisdictional claims in published maps and institutional affiliations. 